\title{
KEDUDUKAN DAN PERANAN ORANG LANJUT USIA DALAM KELUARGA DAN MASYARAKAT
}

\author{
MURLIS \\ STISIP Padang \\ murlis@gmail.com
}

\begin{abstract}
Elderly people can be categorized both socially and biologically. Socially elderly people are characterized by a person's age, because age is our interaction with other people in the social environment. With certainty, old age cannot be determined because socially elder people will be treated like parents, even though they do not feel old. In the social stratification of the elderly, there will be changes in social status and social roles. In modern society, the existence of parents in the child's family can be a problem, namely it can interfere with the economic life of the child's family, shared affection, and perhaps household problems due to the involvement of parents in the child's family affairs. The tendency of modern society today to form a nuclear family brings problems with the lives of the elderly. The role and position of the elderly in the family and society are very much influenced by cultural views about aging. Different views on the elderly will make attitudes and respect for elderly people different in society and in the family.
\end{abstract}

Keywords: Position, Role, Elderly People, Family, Society.

Abstrak: Orang lanjut usia dapat dikategorikan secara sosial maupun biologis. Orang lanjut usia secara sosial adalah ditandai oleh usia seseorang, karena usia merupakan interaksi kita dengan orang lain dalam lingkungan sosial. Secara pasti usia tua tidak dapat ditentukan karena secara sosial orang yang dituakan akan diperlakukan seperti orang tua, meskipun tidak merasa tua. Pada stratifikasi orang lanjut usia secara sosial akan menjadi perubahan status sosial dan peranan sosial. Pada masyarakat moderen, keberadaan orang tua dalam keluarga anak dapat menjadi masalah yaitu dapat menggangu kehidupan ekonomi keluarga anak,kasih sayang yang terbagi,dan mungkin masalah rumah tangga karena turut campurnya orang tua dalam urusan keluarga anak.Kecenderungan masyarakat modern saat ini membentuk keluarga inti membawa masalah terhadap kehidupan para lanjut usia. Peran dan kedudukan lanjut usia dalam keluarga dan masyarakat sangat dipengaruhi oleh pandangan kebudayaan mengenai lanjutusia. Perbedaan pandangan terhadap lanjut usia akan membuat sikap dan penghargaan terhadap orang lanjut usia akan brbeda dalam masyarakat dan keluarga.

Kata Kunci: Kedudukan, Peranan, Orang Lanjut Usia, Keluarga, Masyarakat.

\section{A. Pendahuluan}

Orang berusia lanjut ada menyebutkan dengan istilah lanjut usia (lanjut usia) ataumanula/manusia usia lanjut. Tidak ada keseragaman dalam menetapkan standar usialanjut. Undang-undang Republik Indonesia Nomor 13 tahun 1998 tentang Kesejahteraan Lanjut Usia menyatakan bahwaorang lanjut usia adalah laki-laki atau perempuan yang berusia 60 tahun atau lebih. Di negara maju seseorang dianggap memasuki usia tua pada 65 tahun. 
Organisasi Kesehatan Dunia (WHO) menilai usia 60 tahun adalah awal peralihan menuju kearah segmen penduduk penduduk tua, bahkan di Negara Jepang yang tergolong manusia usialanjut itu diatas 60 tahun dan banyak orang Jepang yang memasuki kesuksesan pada usia 60 tahun, itu sebabnya tidaklah heran bila ada pameo di Jepang yang menyebutkan"lifebegin at 60",Wirakusuma,(2000).

Berkaitan dengan Undang-undang No. 13 tahun 1998, selanjutnya seseorang yang dikatakan dengan orang lanjut usia atau jompo terlantar, menurut UndangUndang No.4 tahun 1976 tentang Kesejahteraan Lanjut Usia adalah :

a. Usia pensiun yaitu antara usia 55 tahun sampai dengan usia 60 tahun.

b. Orang yang tidak mempunyai atau tidak berdaya untuk mencari nafkah sendiri untuk keperluan pokok bagi kehidupannya sehari-hari.

c. Tidak menerima nafkah secukupnya dari keluarga atau kerabat lain.

Akan tetapi menurut John ( Arifin, 2001), orang lanjut usia dapat dikategorikan secara sosial maupun biologis. Orang lanjut usia secara sosial adalah ditandai oleh usia seseorang, karena usia merupakan interaksi kita dengan orang lain dalam lingkungan sosial. Secara pasti usia tua tidak dapat ditentukan karena secara sosial orang yang dituakan akan diperlakukan seperti orang tua, meskipun tidak merasa tua. Pada stratifikasi orang lanjut usia secara sosial akan menjadi perubahan status sosial dan peranan sosial. Sedangkan lanjut usia secara biologis adalah sekumpulan proses yang terjadi secara bersamaan antara kemampuan fisik dan menurunnya daya tahan tubuh terhadap penyakit. Menurunnya kekebalan tubuh terhadap penyakit disebabkan oleh adanya kesalahan molekuler dalam tubuh sehinga terjadi kerusakan sel yang tidak dapat diperbaiki lagi.

Menurut Weg ( dalam Arifin, 2001) mengemukakan ciri-ciri penuaan secara fisik adalah : (1) perubahan fiologis yang terjadi cenderung tetap dan terus menerus selam masa dewasa sampai masa tua, (2) semakin komplek fungsi tubuh, semakin besar media penuaan, (3) usia individu yang berbeda, sistem dan jaringan yang berbeda dalam tubuh sesorang juga mengalami penuaan yang berbeda, (4) penuaan menyebabkan mudah terjangkitnya stress, (5) penuaan mengakibatkan penurunan kemampuan tubuh untuk melawan penyakit.

\section{B. Metdologi Penelitian}

Metode penelitian yang penulis gunakan dalam penelitian ini adalah penelitian deskriptif (descriptive research) dengan menggunakan metode penelitian kualitatif, yaitu di maksudkan untuk pengukuran yang cermat terhadap fenomena sosial tertentu. Metode penelitian kualitatif lebih berdasarkan filsafat fenomenologis yang mengutamakan penghayatan. Metode kualitatif berusaha memahami dan menafsirkan makna suatu peristiwa interaksi tingkah laku manusia dalam situasi tertentu menurut perspektif peneliti sendiri (Nazir, 1990). Metode deskriptif di maksud adalah prosedur pemecahan masalah yang diselidiki dengan menggambarkan atau melukiskan keadaan subjek atau objek penelitian (seseorang, lembaga, masyarakat) pada saat sekarang berdasarkan fakta-fakta yang tampak atau sebagaimana adanya (Nazir, 1990). Penelitian ini akan menjelaskan tentang kedudukan dan peranan Orang Lanjut Usia dalam Keluarga dan Masyarakat 


\section{Hasil dan Pembahasan}

Kemunduran fisik yang menyebabkan orang akan menjadi tuasesungguhnya merupakan suatu fenomena biologis tetapi pengaturan tentang system,kedudukan (status),peranan dan fungsi sosial kelompok orang lanjut usia dalam keluarga dan komunitas adalah konstruksi sosial budaya. (Suwasono, 1989).

Peran dan kedudukan lanjut usia dalam keluarga dan masyarakat sangat dipengaruhi oleh pandangan kebudayaan mengenai lanjutusia. Perbedaan pandangan terhadap lanjut usia akan membuat sikap dan penghargaan terhadap orang lanjut usia akan brbeda dalam masyarakat dan keluarga. Pada suku Minangkabau,orang tua dalam keluarga luas matrilineal dan dipandang sebagai orang yang patut di hormati. Orang tua laki-laki memperoleh gelar kehormatan dan menjadi pemimpin keluarga luasnya atau kampungnya, laki-laki tua (mamak)memberikan nasehat untuk semua masalah terutama masalah adat (Navis,1984), sebagaimana dinyatakan dalam ungkapan kok pai tampek batanyo kok pulang tampek babarito (jika pergi tempat bertanya,jika pulang tempatmengadu).

Pendapat yang sama dikemukakan Afrizal(2001). Dia menyebutkan orang Minangkabau mempunyai hubungan dengan keluarga matrilineal,mereka juga mempunyai hubungan yang berbeda dengan kategori sanak keluarga yang berbeda. Dengan adanya garis hubungan dengan keluarga atas dasar perkawinan. Pada masyarakat matrilineal yang umumnya terdiri dari keluarga luas,memasuki usia lanjut tidak perlu dirisaukan. Mereka memiliki jaminan sosial yangpaling baik yaitu anak dan saudara-saudara lainnya. Anak masih merasa berkewajibanmempunyai loyalitas menyantuni orang tua mereka yang sudah tidak dapat mengurusdirinya sendiri.Nilai yang masih berlaku dalam masyarakat bahwa anak wajib memberikan kasih sayang kepada orang tuanya sebagaimana pernah mereka dapatkan sewaktu mereka masih kecil.

Pada masyarakat moderen, keberadaan orang tua dalam keluarga anak dapat menjadi masalah yaitu dapat menggangu kehidupan ekonomi keluarga anak,kasih sayang yang terbagi,dan mungkin masalah rumah tangga karena turut campurnya orang tua dalam urusan keluarga anak.Kecenderungan masyarakat modern saat ini membentuk keluarga inti membawa masalah terhadap kehidupan para lanjut usia.

Menurut Melly (1984) para lanjut usia mengalami tugas perkembangan terakhir yang harus dijalani agar dapat menikmati masa tua dengan baik yaitu:

a. Menyesuaikan diri pada keadaan menurunnya kemampuan atau kekuatan fisik dan kesehatan.

b. Menyesuaikan diri pada masa pensiunan dan berkurangnya penghasila.

c. Menyesuaikan diri dengan meningglanya pasangan hidup.

d. Membangun hubungan aktif dengan salah satu kelompok sosial yang sesuai dengan umurnya.

e. Berusaha menemukan dan memberikan bantuan sosial sebagai warga negara.

f. Menyusun bentuk dan cara hidup yang disuaikan dengan keadaan fisik mereka.

g. Dekat dengan pusat angkutan umum, tempat ibadah, pusat perbelanjaan, perpustakaan, tempat-tempat hiburan. Akibat adanya stratifikasi lanjut usia adalah penurunan status orang tua dengan indikator penurunan akses sumber daya ekonomi, pengaruh terhadap pembuatan kebijakan. 
Seperti yang diuraikan diatas di Minangkabau, hubungan keluarga merupakan institusi paling penting yang menyediakan tunjangan bagi kaum lanjut usia,dan ini terkait dengan sitem keluarga dan struktur kelompok keluarga dari masyarakat. Oleh karena itu,kita harus memahami sistem hubungan ini beserta struktur cara-cara yang ditempuh oleh masyarakat dalam mensejahterakan kaum lanjut usia.

Menurut Afrizal(2001:399), masyarakat Minangkabau menerapkan sistem hubungan keluarga matrilineal . Dimana afiliasi pada kelompok keluarga dan warisan harta adalah menurut garis ibu,setiap orang akan menjadi bagian dari kelompok keluarga ibu daripadaayah. Keadaan ini mengakibatkan orang Minangkabau akan lebih terikat pada sanak famili ibu daripada sanak keluarga ayah.

Sehubungan dengan kaum lanjut usia di Minangkabau kesejahteraan bagi kaum lanjut usia ini sangatlah diperhatikan,agar lanjut usia nantinya terhindar dari rasa tidak nyaman, hal ini sangat tergantung pada famili, kerabat perempuan harta milik. Hal ini mensyaratkan adanya kerabat perempuan dan kesediaan harta milik meraka.Perubahan sosial dan demografis yang terjadi di Minangkabau sebagai akibat dari pembangunan ekonomi yang mempengaruhi ketersediaan sanak keluarga dan harta milik sebagai sumber tujangan bagi kaum lanjut usia di hari tuanya.

\section{Penutup}

Orang lanjut usia dapat dikategorikan secara sosial maupun biologis. Orang lanjut usia secara sosial adalah ditandai oleh usia seseorang, karena usia merupakan interaksi kita dengan orang lain dalam lingkungan sosial. Secara pasti usia tua tidak dapat ditentukan karena secara sosial orang yang dituakan akan diperlakukan seperti orang tua, meskipun tidak merasa tua. Pada stratifikasi orang lanjut usia secara sosial akan menjadi perubahan status sosial dan peranan sosial. Pada masyarakat moderen, keberadaan orang tua dalam keluarga anak dapat menjadi masalah yaitu dapat menggangu kehidupan ekonomi keluarga anak,kasih sayang yang terbagi,dan mungkin masalah rumah tangga karena turut campurnya orang tua dalam urusan keluarga anak.Kecenderungan masyarakat modern saat ini membentuk keluarga inti membawa masalah terhadap kehidupan para lanjut usia. Peran dan kedudukan lanjut usia dalam keluarga dan masyarakat sangat dipengaruhi oleh pandangan kebudayaan mengenai lanjutusia. Perbedaan pandangan terhadap lanjut usia akan membuat sikap dan penghargaan terhadap orang lanjut usia akan brbeda dalam masyarakat dan keluarga..

\section{Daftar Pustaka}

Agus, Bustanuddin, 2005,Agama Dalam Kehidupan Manusia, Jakarta, Raja Grafindo Persada.

Afrizal, 2001, "Hubungan Keluarga, Manajemen Kekayaan, Perubahan Sosial dan Kesejahteraan Sosial Lanjut Usia di Minangkabau Matrilinial Kontemporer" dalam Franz von Benda-Beckmann dkk. (peny.) Sumber Daya Alam dan Jaminan Sosial. Yogyakarta: Pustaka Pelajar.

-------, 2008, Pengantar Metode Penelitian Kualitatif, Labor Sosiologi FISIP Universitas Andalas Padang.

Blake. L, 1992 Growing Old In The Malay Community. Centre For Advanced Studies

BPS, 2011,Sumatera Barat Dalam Angka, tahun data 2010, BPS Propinsi Sumatera Barat

Beckmann, Franz Von Benda, 2001, Sumber Daya Alam, dan Jaminan Sosial, Yogyakarta, Pustaka Pelajar IKAPI 
Demartoto, Argyo, 2007, Pelayanan Sosial Bagi Lanjut usia, Surakarta, UNS Press

Departemen Sosial RI. 1986. Undang-undang RI No 6 Tahun 1974, Tentang Ketentuan Pokok Kesejahteraan Sosial. Direktorat Jendral Bantuan Sosial, Jakarta

Departemen Sosial RI. 1998. Undang-undang RI No 13 Tahun 1998, Tentang Kesejahteraan Lanjut Usia. Jakarta

Johnson D. P,1986, Teori Sosiologi Klasik dan Modern, Jakarta, PT Gramedia

John R., An Introduction to concept and issues. San Diego: San Diego State University. Terjemahan Arifin, Elfa, (2001). Pertumbuhan Penduduk Dunia. Makalah. Tidak dipublikasikan

JIPTUMM, 2004, Perspektif Sosial Ekomomi Orang Lanjut usia Terhadap Kesejahteraan. Universitas Muhammadiyah Malang.

Huky Will, D. A, 1986, Pengantar Sosiologi, Surabaya, Usaha Nasional

Indrizal, Edi. 2005. Problem Orang Lanjut usia Tanpa Anak di Dalam Masyarakat Minangkabau, Sumatera Barat. Jurnal Antropologi Indonesia. Vol. 29, No 1 Januari 2005. Hal 69-92

Miles, M. B dan Huberman, 1992, Qualitatif data Analysis, Terjemahan Rohidi, Jakarta, Universitas Indonesia Press.

Moh. Sholeh. Imam Musbikin, 2005, Agama Sebagai Terapi Telaah, Yogyakarta, Pustaka Pelajar.

Moleong, Lexy J. 2000, Metodologi Penelitian Kualitatif, Bandung, Remaja Rosda Karya.

Navis, A.A 1984. Alam Terkembang Jadi Guru: Adat dan Kebudayaan Minangkabau. Jakarta : Grafiti Pers.

Nazir, M, 1990, Metode Penelitian Sosial, Jakarta, Gramedia

Soetarso, 1997, Kesejahteraan Sosial, Pelayanan Sosial, Bandung STKS.

Soekanto, Soerjono, 2009, Sosiologi Suatu Pengantar, Jakarta, Rajawali Pers.

Suyanto Bagong, 2010. Sosiologi Teks Pengantar dan Terapan, Jakarta, Rencana Pranada Media Group.

Undang-undang RI No 6 Tahun 1974, Tentang Ketentuan Pokok Kesejahteraan Sosial. Jakarta

Soemarno Nugroho T. 1987. Sistem Intervensi Kesejahteraan Sosial, Hanindita. Jakarta.

Soerjono Soekanto. 1990. Sosialogi Keluarga (tentang ikhwal keluarga, remaja dan anak-anak), Rineka Cipta, Jakarta.

Soetarso, 1997, Kesejahteraan Sosial, Pelayanan Sosial dan Kebijaksanaan Sosial, Bandung : STKS

Wahyudi Nugroho. 1995. Perawatan Lanjut Usia, penerbit buku kedokteran, EGC, Jakarta.

Yun Marga Lita, 2001, Pendidikan Agama Islam Terhadap Orang Lanjut Usia di desa Balai Batu Sandaran Kecamatan Berangin Sawahlunto, IAIN Imam Bonjol Padang 